\title{
Cirrhosis associated with multiple transfusions in thalassaemia
}

\author{
G JEAN, S TERZOLI, R MAURI, L BORGHETTI, A DI PALMA, A PIGA, M MAGLIANO, \\ $M$ MELEVENDI, AND M CATTANEO
}

Ospedale di Gorgonzola, Milan; Cattedra di Puericultura dell'Università di Milano, Milan; Arcispedale S Anna, Ferrara; Clinica Pediatrica dell'Università di Torino, Turin; Ospedale Galliera, Genoa; and Laboratorio di Anatomia ed Istologia Patologica degli ICP di Milano, Milan

SUMMARY The study of surgical liver biopsy specimens obtained during splenectomy in 86 children with thalassaemia indicated that such patients may develop liver disease that evolves into cirrhosis. Histological characteristics suggest that it is post-necrotic cirrhosis. Onset of cirrhosis in some patients may occur as early as 7-8 years old, and at age about 15-16 years most children with thalassaemia show features of cirrhosis. In addition to fibrosis, hepatitis, or even aggressive hepatitis may develop as has also been observed in patients without thalassaemia who have undergone multiple transfusions. This study presents the current probable evolution of liver disease in patients with thalassaemia and may thus serve as a reference from which to evaluate any future progress in the treatment and care of patients with Cooley's disease.

Liver disease in patients with thalassaemia major is due to various causes: haemosiderin overload may provoke hepatocyte necrosis and fibrosis ${ }^{1}$; multiple transfusions may cause repeated episodes of hepatitis that tend to become chronic. ${ }^{2}{ }^{3}$ Progress made in the last decade in the general treatment of patients with thalassaemia and improvements in the organisation of centres for diagnosis and treatment of the disease indicate that it may soon be possible to postpone the onset of secondary haemochromatosis in patients with thalassaemia.

To evaluate the effects of current treatment of thalassaemia we studied systematically the histological modifications in surgical liver biopsy specimens obtained from 1976-81 in children of different ages with thalassaemia undergoing splenectomy. This study differs from our other studies on needle biopsies. ${ }^{2}{ }^{3}$ The series of patients in the present study was not selected on the basis of suspected chronic hepatitis but consisted of patients who underwent splenectomy when liver function tests were not severely altered; in addition the biopsies were surgical and, therefore, of greater diagnostic accuracy.

\section{Materials and methods}

We examined liver biopsy specimens from 86 children with Cooley's disease attending various
Italian centres for the diagnosis and treatment of thalassaemia-namely, Clinica Pediatrica, University of Milan; Galliera Hospital, Genoa; Clinica Pediatrica, University of Turin; and Santa Anna Hospital, Ferrara. The patients were aged between 3 and 16 years when splenectomy was performed according to the usual protocol. ${ }^{4}$

All patients were homozygous but with different molecular defects responsible for $\beta$-thalassaemia because of their different regional origins. It was not possible to obtain the history of each patient's liver disease; the only reliable data available were those obtained at splenectomy (Table).

Only one of the 86 children presented with positive hepatitis B serum antigen ( $\mathrm{HBsAg}$ ), which subsequently remained positive for about 10 years.

Table Clinical data in 86 children with thalassaemia at splenectomy between 3 and 16 years of age

\begin{tabular}{lll}
\hline & & $N o(\%)$ \\
\hline Bilirubin & $>34 \mu \mathrm{mol} / \mathrm{l}(2 \mathrm{mg} / 100 \mathrm{ml})$ & $86(100)$ \\
Serum albumin & $3.5 \mathrm{~g} / 100 \mathrm{ml}$ & $69(80)$ \\
$\gamma$-globulin & $>1.3 \mathrm{~g} / 100 \mathrm{ml}$ & $86(100)$ \\
$\begin{array}{l}\text { Serum asparate } \\
\text { transaminase and }\end{array}$ & Normal & $26(30)$ \\
$\quad$ Serum alanine & Two to three-fold increase & $43(50)$ \\
$\quad$ tramsaminase & Four to six-fold increase & $17(20)$ \\
$\begin{array}{l}\text { Hepatitis B serum } \\
\text { antigen }\end{array}$ & & \\
\hline
\end{tabular}


The other markers were evaluated systematically only in the last four years of our study in a limited number of patients. The data available show that over 12 years of age a positive response for one or more markers (anti-HBsAg, anti-HBcAg, anti$\mathrm{HBeAg}$ ) is constant.

Desferrioxamine was administered intramuscularly according to various regimens at the different centres; only since 1980 has a single protocol been used-namely, specific subcutaneous administration with infusion pumps at a dose of $20-60 \mathrm{mg} / \mathrm{kg} /$ body weight a day for four to 7 days a week.

Histology. The liver tissue was fixed in formaldehyde solution or Bouin's fluid, embedded in paraffin, and examined with haematoxylin eosin stain, van Gieson's stain, silver impregnation, and Perls's test for iron. Five criteria were used to evaluate the degree of fibrosis:

Minimum fibrosis was defined as when only the portal spaces appeared enlarged, due to increase in connective tissue;

Moderate fibrosis was indicated by more or less broad fibrotic bands extending from the portal spaces to inside the acinus;

Massive fibrosis was indicated by formation of portoportal bridges;

Initial cirrhosis was indicated by the presence of some pseudolobules;

Cirrhosis was indicated by the entire biopsy sample having a pseudolobular structure.

In addition to fibrosis, inflammatory infiltrates were always present suggesting non-specific reactive hepatitis, persistent hepatitis, and aggressive hepatitis. 5

\section{Results}

In the course of liver biopsies performed during splenectomy in children with thalassaemia we found four types of lesion in various combinationsnamely, siderosis (constant and massive), hepatic foci of haemopoiesis (mainly in the youger patients), fibrosis in all stages up to cirrhosis, and hepatitis.

As the final development of liver disease in patients with thalassaemia is cirrhosis, we have given particular attention to the evolution of cirrhosis as well as to the alterations that precede it or that may accelerate its evolution. In the younger patients with thalassaemia (3-5 years old) fibrosis was generally limited to the portal spaces that appeared enlarged; later generally active septa appeared (Fig. 1), which formed portoportal and centroportal bridges. These septa delimited the liver parenchyma in areas in which atypical liver cell regeneration producing pseudolobules was subsequently observed (Fig. 2). This evolution towards

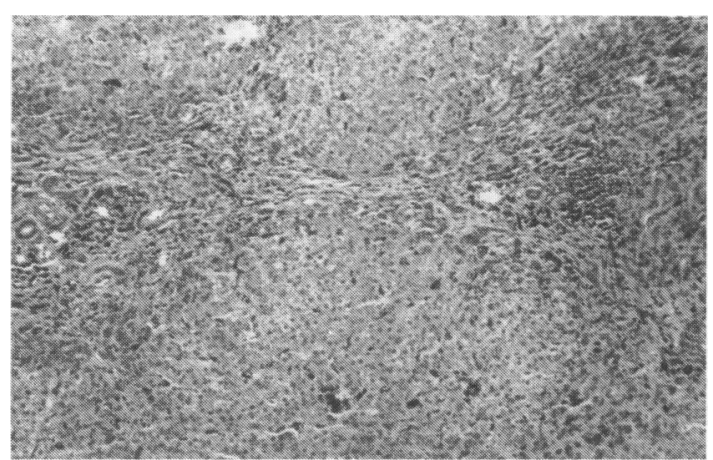

Fig. 1 Liver biopsy specimen from a 7 year old child showing two enlarged and fibrotic portal spaces linked by a fibrotic bridge; the inflammatory infiltration is mild. (Van Gieson's stain $\times 120$ ).

cirrhosis was progressive with age (Fig. 3): there was a minimum increase in fibrotic tissue in liver biopsy specimens only in the patients of 3-5 years; in those over 11 years old cirrhosis was common (11 out of 25 ); and at 15-16 years old most showed cirrhosis. Furthermore, in some patients the onset of cirrhosis was particularly early (8-9 years). It was not possible to identify causes favouring this phenomenon: in fact these children did not differ appreciably from those in whom cirrhosis developed later in the number of transfusions received, the number of previous episodes of acute hepatitis, or the inflammatory histological picture; also the patterns of the hepatitis B virus markers were similar.

Portal spaces and newly formed septa were usually the sites of inflammatory infiltrates, which consisted of lymphocytes, plasma cells, fibroblasts, and macrophages full of haemosiderin. In addition,

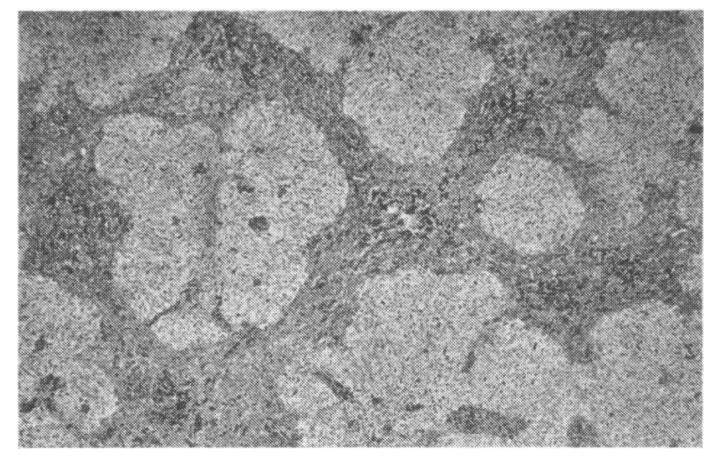

Fig. 2 Liver biopsy specimen from a 13 year old child showing macronodular cirrhosis with thickened bands; the inflammatory infiltration is still present. (Van Gieson's stain $\times 48$ ). 


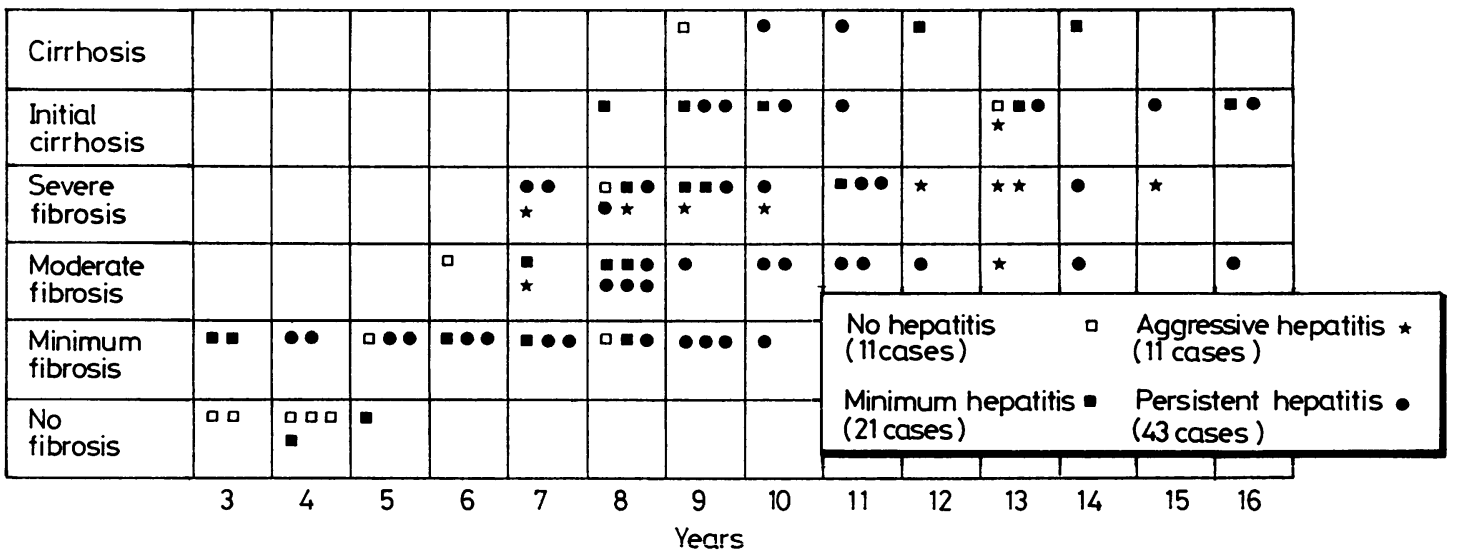

Fig. 3 Liver disease in 86 children with thalassaemia according to age. $\square$ indicates no hepatitis; $\square$ indicates minimum hepatitis; $\star$ indicates aggressive hepatitis; $O$ indicates persistent hepatitis.

inflammatory foci were noted inside the liver parenchyma near islands of necrotic hepatocytes with occasional Councilman's bodies. Thus, patterns were observed of non-specific reactive hepatitis (21 cases), persistent hepatitis (43 cases), and aggressive hepatitis (11 cases).

\section{Discussion}

Liver disease in patients with thalassaemia is one of the best known examples of erythropoietic haemochromatosis. ${ }^{1}$ 6-9 Studies with an electron microscope of liver biopsy specimens from children with thalassaemia have shown that the deposition of collagen occurs very early in life (age 3-13 months), starting in Disse's space and seeming to precede hepatocyte necrosis? This early fibrinogenesis cannot be observed with a light microscope; instead portal fibrosis can be seen (at 3-5 years), which is followed by the formation of fibrous septa, generally active, consisting of portoportal and portocentral bridges. In this way prevalently macronodular posthepatitis cirrhosis develops; the incidence of cirrhosis increases progressively, so that at $15-16$ years almost all the children with thalassaemia that we studied showed features of cirrhosis.

In previous observations we made on needle biopsies the high incidence of chronic hepatitis in multiply transfused patients with thalassaemia was emphasised $;{ }^{2}{ }^{3}$ it is probable that this phenomenon is also due to the high incidence of hepatitis B virus infections in the Italian population. ${ }^{8}$ The present observations on surgical liver biopsies (in children who did not present with severely altered results to liver function tests) confirm our previous results: of
86 patients, 75 showed features of hepatitis including 11 of aggressive hepatitis. This finding is similar to that in series of other patients without thalassaemia who have undergone multiple transfusions. ${ }^{9-12}$

These observations underline the fact that in patients with thalassaemia the problems connected with progressive liver impairment are becoming increasingly serious, especially now that improved transfusion and support treatment delay the onset of heart failure. Possible ways of delaying the evolution of liver disease that in patients with thalassaemia develops into cirrhosis, include treatment with desferrioxamine given subcutaneously with continuous infusion pumps, ${ }^{13}$ vaccination against hepatitis virus, and antiviral drugs; the usefulness of steroids still seems rather limited even in cases which suggest aggressive hepatitis. ${ }^{3}$

In conclusion, we believe that our findings accurately reflect the likely development of liver disease in patients with thalassaemia in north Italy in the years 1976-81. They thus may serve as a reference from which to evaluate the efficacy of new methods of treatment, better health care, and better social services in improving the prognosis of patients with thalassaemia.

\section{References}

${ }^{1}$ Powell LW, Bassett ML, Halliday JW. Hemochromatosis: 1980 update. Gastroenterology 1980;78:374-81.

2 Masera G, Jean G, Gazzola G, Novakova M. Role of chronic hepatitis in development of thalassaemic liver disease. Arch Dis Child 1976;51:680-5

${ }^{3}$ Masera G, Jean G, Conter V, Terzoli S, Mauri RA, Cazzaniga M. Sequential study of liver biopsy in thalassaemia. Arch Dis Child 1980;55:800-2

4 Modell B. Total management of thalassaemia major. Arch Dis Child 1977;52:489-500 


\section{Jean, Terzoli, Mauri, Borghetti, Di Palma, Piga, Magliano, Melevendi, Cattaneo}

5 Popper H, Schaffner F. Chronic hepatitis: toxonomic, etiologic and therapeutic problems. In: H Popper, F Schaffner, eds. Progress in liver disease. Vol. 5. New York: Grune and Stratton, 1976:531-58.

${ }^{6}$ Diebold J, Camilleri JP. Foie et affections du sang. Paris: Masson, 1974.

${ }^{7}$ Iancu TC, Neustein HB, Landing BH. The liver in thalassaemia; major ultrastructural observations. In: Iron metabolism. Ciba Foundation Symposium 51. Amsterdam: Elsevier NorthHolland, 1977:293-307.

8 Verme G, Piccinino F, Rizzetto M, Giusti G. I portatori dell'antigene Australia (HBsAg); problemi attuali. Il Fegato 1980;27:81-114.

9 Aach RD, Shields HM, Lander JJ, Perrillo RP, Zuckerman GR. Post-transfusion hepatitis leading to chronic hepatitis. Gastroenterology 1978;75:732-41.
${ }^{10}$ Preston FE, Triger DR, Underwood JCE, et al. Percutaneous liver biopsy and chronic liver disease in haemophiliacs. Lancet 1978;ii:592-4.

11 Berman M, Alter HJ, Ishak KG, Purcell RH, Jones EA. The chronic sequelae of non-A, non-B hepatitis. Ann Intern Med 1979;91:1-6.

12 McGrath KM, Lilleyman JS, Triger DR, Underwood JCE. Liver disease complicating severe haemophilia in childhood. Arch Dis Child 1980;55:537-40.

13 De Virgilis S, Cossu P, Sanna G, et al. Iron chelation in transfusion-dependent thalassaemia with chronic hepatitis. Acta Haematol (Basel) 1982;67:49-56.

Correspondence to Dr G Jean, Ospedale di Gorgonzola, 20064 Gorgonzola, Milan, Italy.

Received 5 September 1983 